\title{
Ética y política de la función pública
}

\author{
Ethics and politics of public function
}

\author{
Miguel Angel Villalobos Caballero ${ }^{1 *}$ \\ ${ }^{1}$ Facultad de Derecho, Universidad Continental, Huancayo, Perú
}

\section{RESUMEN}

En la historia de la república peruana y de Latinoamérica se advierte que aún no se logra salir del subdesarrollo social, existe todavía en muchos lugares de Sudamérica graves índices de analfabetismo, pobreza, enfermedad y desempleo en perjuicio del avance económico y social de los pueblos, lo cual hace que surja la pregunta ¿2ué hacer?. Consideramos que estos males sociales son responsabilidad de nuestras autoridades políticas, judiciales, sociales $u$ otras, por cuanto ellas, no priorizaron una eficiente gestión pública compatibilizando la acción política con la ética pública. La ética en la gobernabilidad permitirá darle un giro positivo a la gestión pública. Por lo tanto, la ética como la política deben ser herramientas democráticas y sociales del poder estatal para salir del subdesarrollo, entendiendo a la ética como una guía de hacer lo correcto en busca de valores y principios que contengan paz social, seguridad jurídica, bienestar común, libertad y dignidad humana, es decir, valores y fines éticos que luchen contra una sociedad codiciosa y prejuiciosa producto de cierta enfermedad estimativa que no canaliza, ni prioriza el cambio real que debe existir en toda gestión pública a favor de los pueblos.

Palabras clave: República peruana, gestión pública, burocracia, subdesarrollo.

\begin{abstract}
In the history of the Peruvian and Latin American republics it is noticed that it is not yet possible to get out of social underdevelopment, there are still in many places of South America serious illiteracy, poverty, sickness and unemployment indexes in detriment of the economic and social progress of the peoples, which raises the question What to do? We consider that these social ills are the responsability of our political, judicial, social or other authorities, because they did not prioritize efficient public management, making political action compatible with public ethics. The ethics governance will allow a positive change to public management. Therefore, ethics as politics must be democratic and social tools of state power to get out of underdevelopment, understanding ethics as a guide to doing the right thing in search of values and principles that contain social peace, legal security, commom well-being, freedom and human dignity, that is to say, ethical values and ethical purposes that fight against a greedy and prejudiced society product of certain estimative illness that does not channel, nor prioritize the real change that must exist in all public management in favor of the villages.
\end{abstract}

Keywords: Peruvian republic, public management, bureaucracy, underdevelopment.

Historial del artículo:

Recibido, 04 de marzo 2016; aceptado, 18 de febrero de 2017; disponible en línea, 25 de junio de 2017

* Fiscal Superior Titular en lo Penal del Distrito Fiscal de Junín, miembro de la Asociación Internacional de Fiscales (IAP), docente de la Universidad Continental y la Academia de la Magistratura Lima.

Correo: boss.villalobosch@gmail.com 


\section{INTRODUCCIÓN}

Es importante preguntarnos como personas, comunidad y Estado filosóficamente żpor qué un ensayo sobre ética y política en la función pública? Sencillamente, porque en nuestro país y a manera de plaga en Latinoamérica, ya hace buen tiempo, los espurios negocios vinculados -muchas de ellas encubiertas en empresas- a la delincuencia común y organizada han malogrado al gobernante y a la gobernabilidad de los países, por lo que ahora, más que nunca la función pública y la política deben arreglarse desde el camino de la buena política y la real ética dialécticamente enlazadas con fines de bien común ciudadano, siendo acertado pensar, como sostiene Miró Quesada (2013) "el fraude, el engaño, producto de la demagogia, las medidas políticas orientadas a satisfacer los intereses de un grupo de poder y no de las mayorías en busca del bien común, están reñidas con la ética. La ética es filosófica."

La ética pública en la gestión de gobierno debe convertirse en un paradigna político si pretendemos alcanzar el desarrollo justo de la sociedad. Este paradigma debe ser impulsada por los líderes políticos decentes y las nuevas generaciones, a partir de los movimientos juveniles que rechazan cada vez más en el mundo y en nuestro país el sistema de corrupción en la acción de gobierno. "Una generación es una variedad humana, en el sentido riguroso que dan a este término los naturalistas. Los miembros de ella vienen al mundo dotados de ciertos caracteres típicos, que les prestan una fisonomía común, diferenciándolos de la generación anterior" (Ortega y Gasset, 1923).

Las generaciones pasadas -y también las actuales- en muchos casos, sufren de cierta enfermedad estimativa, que en términos de Ortega y Gasset, es "cuando se hace constitutivo en una persona, en una época, en un pueblo, cierto error de preferencias y llega a serle habitual anteponer lo inferior a lo superior subvirtiendo los rangos objetivos de los valores, se trata de una perversión, de una enfermedad estimativa" (Ortega y Gasset, 1923). Por lo pronto, vemos que dos grandes males mueven nuestra sociedad peruana y Latinoamérica: La corrupción y la inseguridad ciudadana. Esta situación es preocupante en una sociedad que cada vez más en vez de insertar buenos elementos humanos, inserta lo malo, que solo son detectados en su peor momento, y cuando la crisis ha agobiado terriblemente en perivicio de todos los ciudadanos, limitando un avance serio de la nación y de la población que solo pretende ser democrática y social.

Democrática, como forma de gobierno y social porque quiere llegar a las mayorías; en ese sentido, se debe apuntar como fines, más a la inclusión, que al juego de la exclusión.
Por tanto, este trabajo quiere demostrar que mientras no se estandarice la función pública a niveles de real función pública y de real política, en el sentido de servir y no de servirse de ella, no se reducirán los niveles de corrupción.

\section{El paradigma del cambio ético en la gestión pública}

¿Cómo entender paradigmáticamente un cambio de progreso ético y político para la mejora de la función pública? La primera respuesta es, tener conciencia de la virtud de la función pública, de algo que puede ser, $y$, que viene ligada a la decencia, la honestidad, la probidad, la capacidad y otras cualidades más que dignifican el cargo, sea este por nombramiento o por encargo (cargos de confianza); a diferencia del vicio en la función pública que viene ligada a la deshonestidad, incapacidad y otros trastornos que generan corrupción del ser y del cargo público.

Es así, que para progresar y mejorar la sociedad, hay que entender el problema, no es cuestión de ser ético literalmente, sino entender "lo ético" y "lo político" en conceptos puros, cada uno y por separado, que hay por allí tantas virtudes por internalizar y tantos vicios por desechar, que en ese camino ético personal y social está la política que puede frenar en cierto modo la corrupción como vicio de la sociedad, que desmejora la vida honesta personal y ciudadana, esa es una cuestión ética que todos debemos de reflexionar.

En Democracia hay que tener cuidado con los eufemismos o camuflajes que hacen los gobiernos que ganan en las urnas (elecciones), pero luego se tornan despóticos o dictatoriales, cuando hablan de teorías, como la del "Buen Gobierno", porque por más óptimo resultado que se consigan en la gestión presidencial o del partido, no es adecuado ni democrático, ni siquiera vía urna, la perpetuidad en el gobierno de los pueblos (Villalobos, 2010). Este eufemismo o camuflaje se puede volver viral, como fue la dictadura militar en su momento en Latinoamérica, eufemismo o camuflaje como mal ético y político en ciertos lugares de Latinoamérica, que no entienden, el ser democrático de los pueblos, cuando, pretenden perpetuarse en el cargo a su mero capricho.

Curiosa también resulta la siguiente pregunta, tantas veces repetida: ¿̇En qué momento se jodió el Perú?, reformándola podría ser mejor preguntar ¿̇En qué momento se jodió Latinoamérica? Y la respuesta tentativa es tal vez, cuando se comenzó a actuar políticamente de manera errónea por apetitos personales en perjuicio del Estado, ya sea perjudicando como gobernante (hasta que se les descubre en sus reales facetas y ante la intervención de la ley, el Orden y la justicia) o perjudicando como ciudadano al tolerar lo intolerable (una especie de esquizofrenia 
colectiva, de aguantar el dolor del mal gobierno sin frenar, ni chistar nada), como es apartarse de los fines de la patria o actuando de manera irresponsable, inadecuada y despreocupada como persona o comunidad en general.

Lamentablemente el país se perjudicó más cuando se hizo todo para que la realidad continúe igual. En realidad, el Perú se torció para no cumplir sus reales fines: la paz, la democracia, la gobernabilidad, la honestidad, por las siguientes razones: a) por algunos de sus malos gobernantes; b) por la falta de voluntad de los ciudadanos de no querer enderezar esos malos hábitos, como no pagar impuestos, aceptar cargos sin tener la capacidad para ello, incorporar el mal valor social contemporáneo del rumor -vía social y mediática-, que desgasta a la persona y distrae al ciudadano, para dar pase libre a ese tema oculto pero real; la corrupción, que pretende enquistarse cada vez más, en las instituciones.

Claro está que en estas situaciones de desmejora social, la culpa no solo es nuestra, con nuestros malos hábitos, sino también de los gobernantes de turno con sus codicias y egoísmos -sus negocios y amigos ocultos- desde dictadores sin respeto por los derechos fundamentales hasta los malos demócratas con sus elaboradas persuasiones sociales de bienestar que encubren sus apetitos individuales y grupales, Quiroz (2014) al respecto manifiesta que, la corrupción no solo viene desde la República sino desde la época de la Colonia, y continua con ritmo propio hasta la actualidad.

\section{¿̇por qué es tan difícil reformar la justicia en América Latina?}

Se pregunta Luis Pásara (2014); ¿Qué esperar?, replica. Su respuesta no debe ser desalentadora, sino, por el contrario paradigmática, de que las cosas no pueden seguir como hasta ahora, de lo contrario, no tendría sentido ni la dialéctica, ni el cambio que vio Heráclito (540-480 a. C.) al ver que nadie puede bañarse dos veces en las mismas aguas de un río, ya que todo fluye, consecuentemente, aunque la corrupción en latinoamerica está rondando, tarde o temprano, ésta disminuirá, todo es cuestión de una nueva generación de latinos dispuestos a no soportar más este deterioro moral que penetra la política, la administración pública y sus apetitos feroces en perjuicio de la comunidad.

Joel Barker (2016) refiere sobre los paradigmas que no solo es un modelo sino una nueva manera de ver las cosas; La siguiente anécdota ilustra el caso. Un colega magistrado viajaba de la ciudad de Lima a la sierra peruana. Era mediodía de un domingo. En el trayecto encontró muchas quebradas, subidas y bajadas, lba en un auto moderno de color rojo, con una velocidad promedio, cuando de pronto una señora de contextura gruesa, que con su auto pasaba por su lado en sentido contrario a regular velocidad, le grita: "iCerdo!", "icerdo!". Él la miró, en el acto contesta: "iVaca!", "ivaca!", perdiendo de vista a la inusitada conductora. Tras unos minutos, a pocos metros, y cuando doblaba con dificultad una curva, el magistrado se tropieza inesperadamente con un cerdo, situación que puso en riesgo al animal. La señora, en la lección de esta anécdota, no quiso ofenderlo a mi colega, solo pretendía avisarle de un peligro inminente; quería ayudarlo a evitar peligros, pero: ¿Qué pasó?. Simplemente funcionó mal paradigma: "tú me ofendes, yo te ofendo"; en la práctica él consideraba: "si yo soy un cerdo, tú eres una vaca".

Así, no necesariamente, todos son malos funcionarios públicos, o que todos son malos gobernantes, porque lo político, el buen gobierno o la buena gestión o función pública no es mala en sí, sino que es necesario un verdadero camino de reflexión, mejor dicho, de autorreflexión, del que tiene el cargo público, para pensar ¿̇En qué está fallando y en qué puede mejorar?.

De este modo, la ética debe ser entendida como la reflexión de los comportamientos humanos buenos, y la política como el arte de hacer lo mejor posible en lo social, es decir: "en servir" y "no en servirse del ciudadano", reflexionando sobre el "paradigma de la buena función pública".

Así, imaginemos la imagen de una persona que aparentemente tiene una vida correcta, como un profesional de la justicia: un magistrado judicial, que hace justicia aparente, nunca resuelve conforme a ley y a su conciencia, sino, a lo que prioriza su interés hace aquello que le conviene, aunque la sociedad se desgracie con su mal actuar.

$Y$ es que hay que saber diferenciar entre lo que es la "ética" de lo que es la "moral". La ética vendría hacer lo teórico, lo imaginario, no lo abstracto de lo que debería ser una buena persona en su conducta humana, como padre, como profesional; en cambio, moral, es aquello que es la consecuencia de lo que se dice, de lo teórico, por decir, si yo éticamente señalo ser un buen profesional, pero, llego tarde al trabajo, no cumplo con mis funciones o las deformo (me enriquezco en el cargo), asimismo, no me comprometo con la institución y demás, no soy moral, no hago lo correcto, por cuanto, no soy consecuente con lo que digo que soy.

En el Derecho Penal ocurre que al cometerse un delito, difícilmente, alguien lo acepte, por decir, aceptar haber cometido un delito contra la Administración Pública, porque en filosofía moral es inmoral aceptar la responsabilidad de algo, algo que te descalifique, por lo tanto, nadie se autoreprocha, razón, por el cual, 
cuando alguien confiesa o acepta responsabilidad penal, recibe a cambio, una serie de beneficios contenidos en el conocido "Derecho Premial", como es la reducción de la pena u otro beneficio, alguien colabora y a cambio recibe beneficios.

Sin embargo, en cuanto a tu conducta como funcionario público no es tanto pecar o cometer delito, para luego confesar y recibir "una especie de Derecho Premial", aquí si bien tienes derechos como funcionario público, también, tienes deberes y obligaciones, dentro de estas obligaciones, está, el debido comportamiento que debes adoptar frente a la administración pública y a la cosa pública, entre ellos, la lealtad frente a la administración pública, incluso, no solo en la actividad pública, sino, también si se da el caso, en la actividad privada.

El deber debe ser objetivo, no es que con esta persona me porte bien y con aquel otro, muy mal, el deber debe ser intacto para dar a todos el mismo trato o servicio público, y, esto conforme a las normas e instrucciones de vuestra institución.

Al respecto Leclercq (1960) decía que cada uno de nosotros tenemos preceptos, nosotros diríamos, tendencias y conciencias: a) religiosa, b) social y c) moral, así, muchas personas generalmente aceptan conductas socialmente aceptadas, tal vez, en una época es correcto socialmente mentir, u apropiarse, o vestir de tal modo, pero, esto es relativo.

Lo correcto es tener siempre una conciencia moral, pero, para adquirir ésta se debe eliminar ciertos lastres, que impiden la evolución del pensamiento humano, en ese sentido David Hume precisa cuatro lastres: a) la ignorancia, b) la superstición, c) el miedo y 4) la intolerancia.

Así, un funcionario público, no debe tener una ignorancia total o absoluta de conocimiento, debe esforzarse, cada día más por aprender o conocer algo de su oficio o de la gestión pública, algo que lo fortalezca en conocimiento cierto.

Otro lastre, que no deja avanzar culturalmente, es la superstición, aquello que se cree que puede pasar negativamente, ejemplo, ver un gato negro o pasar debajo de una escalera, no es anticipo de desgracia, pero pensar así es una situación intolerable, en época moderna y contemporánea, que no debe permitirse, se debe usar la lógica, lo racional.

También, el miedo afecta en la función pública, cuando un funcionario público debe ser valiente -sin miedo a la prensa, a los comentarios negativos- lo único que debe interesarle es hacer lo correcto, fijar posición ante los demás.
Por último, la intolerancia, es un lastre porque no permite la socialización, y genera división. Hay que ejercitarse en la vivencia de valores, entre ellos los buenos, los estéticos, los justos, pero siempre siendo tolerantes, apreciar la diversidad, el pluralismo de los pensamientos, de las cosas y de las situaciones, como lo hizo Europa en su momento, que países divididos después de la primera y segunda guerra mundial se integraron como Comunidad Europea en base al Principio de Integración y Principio de Supremacía del Derecho Europeo frente a un Derecho Nacional, entendiendo, que pueden vivir en comunidad y cediendo soberanía pero respetando sus tradiciones nacionales.

\section{Caminos para ser un buen funcionario público}

Entendiendo la naturaleza de las cosas, un gran intento de conocer fue la propuesta de René Descartes, cuando señalaba cogito, ergo sum, es decir "Pienso, luego existo", por cuanto es a raíz de Descartes, que se marca una diferencia, entre, Edad Medieval y Edad Moderna, ya no aplicando "la fe" sino "la razón" para entender la naturaleza de las cosas, sin embargo, en ese camino de conocer la esencia, solo descubrió la subjetividad humana; es ahí, donde años posteriores entra a tallar Edmund Husserl, el maestro alemán, que enseña a través de su fenomenología, que es posible, conocer el fenómeno, la esencia en sí, sea este el Arte, Derecho, o cualquier imagen o ente que aparezca y queramos conocer, para lo cual, aplicó lo que se conoce como el epojé fenomenológico, que no es otra cosa que poner entre paréntesis lo que debe ser conocido, por ejemplo, ¿̇qué es la función pública?, ¿̇se puede ejercer decentemente la función pública? y otras interrogantes más; nosotros, pensamos ponerle un paréntesis al objeto de estudio de las preguntas, $y$, poner dentro nuestros buenos o malos deseos, pensamientos, criterios, prejuicios y otros, solo, pretendamos conocer ingenuamente como si fuésemos un niño, sin prejuicio alguno, a fin de llegar al objeto requerido, así, saber para el presente ensayo, en qué consiste la función pública y saber si se puede ejercer decentemente.

Ahora, utilizando el camino cartesiano o husserliano para conocer respecto a la función pública -una acotación- por ejemplo, ser funcionario público, requiere de ¿̇Una buena o de una mala persona?, obvio está, que una mala persona deseara lo peor para la función pública, su incapacidad en el cargo, tampoco ayudara, para ser un buen funcionario público además de ser una buena persona, es necesario que se estime asimismo como persona o como ser social, y, sobre todo, estime al mundo que le rodea, que sería lo mejor, para que el cargo de funcionario público lo ejerza con dignidad, esto sería implícitamente utilizar una buena política con ética. Aparte de ello, sería 
bueno que el sistema político sea siempre el adecuado -el democrático- que en el mundo a pesar de estar por encima del siglo XX, vive en caos, con atropellos, dentro de una cultura de transgresión, con ciertas violaciones a los derechos fundamentales, en el cual la buena política ya no se da, la política desde épocas griegas ha sido una amplia preocupación, en especial, de los politólogos.

La política como una buena creación humana permite en su buen ejercicio vivir con dignidad, respetando a las minorías, incluyendo y no excluyendo, es decir, un conjunto de características que le den sentido a vivir en sociedad, el ser político debe ser una causa de admiración.

Es así que la política se puede ejercer con dignidad y con plena libertad, para ello, sirve y nos orienta la ética, para ejercer con actos morales dignos y no despreciables.

Kant señaló que en el mundo de las percepciones se ven dos entes: las personas y las cosas, en grado jerárquico, a la manera de Max Scheller, que la persona representa un grado superior, mientras que las cosas, representan un grado inferior, por eso, cuando una persona que tiene dignidad se degrada a una cosa que se vende, es moralmente despreciable.

Este pensamiento Kantiano es importante por cuanto la moral es importante en la vida humana, con mayor razón será en la vida pública, es decir, en la función pública, en una vida con compromisos que hay que honrar.

Es decir, hay que cuidar la función pública, pesa a las dificultades actuales, hay que arreglar la función pública, o ¿̇porque se tiene que tolerar cada cierto tiempo, un escándalo en la vida pública?, y, peor generado, ¿̇Por qué se tiene que tolerar cada cierto tiempo un escándalo en la vida pública por nuestras propias autoridades que deberían ser ejemplares? No se trata de decir socialmente está en crisis la función pública y no hay nada que hacer; es falso, hay mucho por hacer y arreglar, no es una situación de genética social o personal o de historicidad nacional acerca de una mala función pública, por cuanto hay que cambiar de paradigmas, no esperar que nos digan "cerdos" para decir, "vacas", simplemente debemos cambiar de paradigma.

La política es el camino personal y social para hacer bien las cosas, con reglas, principios, valores, ese es el deber del gobernante de no turbar la buena función pública y la vida del ciudadano. La Ética es el camino adecuado de llevarnos a ello.

Si bien es cierto existen maneras de controlar el buen ejercicio de la función pública, como son, los órganos de control interno, pero eso debe ser en casos extremos, tal vez, el mejor control interno, a parte del control que ejerza cada institución, es nuestra moral, es decir, no tanto lo social o lo religioso, sino aquella moral recta e inquebrantable adaptada a ideas de lo que realmente debe ser el humano en funciones, es decir, aquellas, ya establecidas por la Ética y los Códigos Éticos.

Lo importante no solo está en tener un buen gobernante, hablando de política, a la manera de la idea Griega Clásica, que buscaban un filósofo, en hallazgo de "lo bueno, lo bello y lo justo", sino, un gobernante actual, que no se crea dueño o amo del poder, que entienda los distintos roles y funciones del aparato estatal, que entienda de la rotabilidad en el cargo, el respeto a los derechos humanos y sobre todo del respeto a los derechos fundamentales de cada cual con tolerancia a las minorías, eso, es ejemplo de Pluralismo Político y de un avance hacia una paz común.

La política se entenderá mejor en el ejercicio de la función pública y en todo, cuando los principios estén por encima de los apetitos económicos y de otra índole. En este campo debe siempre actuarse con sobriedad y sin egoísmos, el Estado se ha creado para servir y no para que un grupo o algunos se apropien de él y cometer lo que sanciona la ley y la ética pública.

En la función pública está el progreso de una Nación, y la Ética y la Política son buenas fuentes de apoyo cuando se les utiliza con sobriedad; en esta ardua labor está la persona humana que ejerza el cargo con dignidad, en la que si por alguna razón se equivocó, sepa volver al camino de la corrección, es mejor, que abandone sus malos hábitos antes que lo descubran y rectificando, actúe altruistamente por la institución, antes que sea una cifra más, de la alta, mediana o baja criminalidad.

No se debe esperar que el Derecho funcione para el mal funcionario, ni la imprescriptibilidad de sus delitos, mejor, es la prevención, el compromiso social, institucional, volver a la razón pura y no dejar suelto lo disoluto o mal instinto que se pueda tener.

De la necesidad de entender al ser humano para un buen ejercicio de la función pública, una pregunta que siempre intriga żes el ser humano bueno o malo? y recurriendo a los grandes filósofos, podemos, decir que, una respuesta es que es bueno y la sociedad lo pervierte, sin dejar, de pensar que también el hombre es bueno por naturaleza, hasta llegar a la idea central de Hobbes, de pensar que el hombre en un estado de naturaleza se vuelve Lobo para los otros, preferimos la idea sartreana, de que el hombre es lo que hace, así, si miente es mentiroso, si roba es ladrón o si mata es un asesino, así, żcuán necios pueden ser los seres humanos al no orientar su acción a fines comunes, entre ellos, la paz?; ¿̇para qué arriesgar la cordura por 
un sentimiento trágico de la vida?. Pero, esto que podríamos llamar la naturaleza humana que es independientemente de la condición humana, podría entenderse mejor, a través de saber, lo que el ser humano pretende, o lo que realmente necesita o desea satisfacer para sí, conociendo sus motivaciones básicas, así, tomando, a Sánchez (2005) señala que "las motivaciones básicas del actuar de las personas, son las siguientes: a) la necesidad de seguridad física, b) la necesidad de seguridad emocional, c) la necesidad de reconocimiento social (estatus) y d) la necesidad de triunfo. Estas últimas, la necesidad de reconocimiento social y la de triunfo son las fuerzas impulsoras decisivas que mueven al hombre tanto para el goce económico como para la búsqueda de Poder".

Este reconocimiento social y la necesidad del triunfo podrían ser las causas torcedoras de la voluntad que no permita una buena función o gestión pública, eso, sin tocar, los trastornos de los valores o vicios, como, son actuar con codicia, egoísmo, deshonestidad, y arrogancia.

Solo entendiendo cabalmente al ser humano, en su naturaleza, podría, ser posible escoger a los mejores -los éticos- para los cargos públicos, tradicionalmente, se ha fallado, esto lo vemos desde la colonia virreinal (comprando títulos y cargos), el inicio de la República y hasta nuestros días, en la que no se escoge bien al gobernante y de aquellos, que deben acompañarlo en la administración pública, para ejercer la función pública a favor de la Nación, esta falencia, y esta terquedad de escoger un mal funcionario, se repite en muchos lugares de Latinoamérica, por eso, tenemos problemas que saltan en común, como es que un grupo que no apunta hacia fines de interés nacional se apodera y aprovecha del Poder, actuando malas gestiones y perjudicando económicamente con substracción de bienes y capitales a favor de intereses y apetitos extraños al pueblo, un ejemplo de ello son los escándalos en Brasil y sus efectos en Perú, que por la labor de los delatores se les ha descubierto a delincuentes, entre ellos, a muchas autoridades de gobierno.

Importante lo señalado por Jorge Carpizo cuando señala que "Los mayores peligros para la democracia en la región latinoamericana no son de índole política sino social, como la pobreza y la gran desigualdad, la carencia de bienes educativos, de protección a la salud y de trabajo; en resumen el bajísimo nivel de vida que sufre la mitad de su población" (Carpizo, 2008).

Al pensar que la idea de ejercer una función pública es imposible o posible, tal vez, se piensa como fracaso o éxito, en ese sentido, acogemos la idea de Oliver Reboul, cuando señala, "fracaso y éxito sólo se comprenden a partir de un fin: el fracaso es el objetivo fallido; el éxito el objetivo alcanzado", más adelante señala "Pensamos, que, si el éxito es un valor, el fracaso también, a condición (en ambos casos) de que sepamos sacarle partido, hacer del fracaso o del éxito una enseñanza", por último, dice: "Naturalmente eso no es fácil. Pero pensamos que la mejor parte de la educación, la más auténtica, es aprender a sacar partido de los fracasos; es el más bello de los éxitos" (Reboul, 1999).

Por eso la idea de cambiar de paradigma en la función pública de cuestionada a exitosa, no depende tanto, de grandes edificios, o una gran infraestructura gubernamental, depende más, de la persona, de su conciencia, de su ética y en gran parte del sistema político que debe estar conforme al humanismo y la ética que rodea la sociedad en particular.

\section{CONCLUSIONES}

Desde la revolución francesa a nuestras fechas, el Estado que era la nueva esperanza de las civilizaciones, en especial, en Europa y ahora en Latinoamérica, no funciona o no es útil como se esperaba, en realidad el Estado le ha fallado a las esperanzas de la población en gran porcentaje, el Estado clásico es un nudo, un tremendo nudo que no es fácil desatar, pues el Estado no se respeta a sí mismo, permitiendo desfalcos, contubernios, apropiaciones y enriquecimientos ilícitos, entre otros males más, ello aunado, a malos gobiernos, dictaduras, y malos demócratas, porque demócrata que permite al corrupto o la corrupción no es un demócrata es otro corrupto más.

Debemos generar nuevos paradigmas para el cambio deseado, en la que la Educación con valores es urgente y necesario, comenzar un proceso de sinceramiento por parte de la autoridad y del ciudadano, para generar nuevos hábitos, y un total aniquilamiento de las viejas mañas y costumbres arraigadas y contrarias a principios, reglas y directrices a favor de un Estado eficaz y de buen desempeño de sus funcionarios públicos para un buen ejercicio de la función pública.

Se propone un sistema de funciones públicas que sepa coordinar objetivamente a la luz de la Constitución Política y los derechos fundamentales, a fin de que no se tropiecen, como puede ser un Ministerio Público ejemplar y un Poder Judicial certero y severo para aquel que no respete las arcas del Estado.

El "Paradigma del buen funcionario" es un objetivo a cumplir con voluntades y conciencias, es lo que se necesita unir con honradez; el hombre no es algo que nace bueno y la sociedad lo pervierte, tampoco es el lobo del hombre, el hombre es libertad y dignidad, dignidad para saber elegir su bien, y si va hacer vida en común es imprescindible, que lo haga con virtud. 


\section{REFERENCIAS BIBLIOGRÁFICAS}

Barker, J. (2016). Paradigmas, el negocio de descubrir el futuro. (Citado el 24 de Noviembre de 2016). Disponible en: https://www.youtube.com/playlist?li st=PLLEFMIPu0izWrtISX_ygSTw5GBQ9x6hLf

Carpizo, J. (2008). Concepto de democracia y sistema de gobierno en America Latina. Lima: Idemsa.

Leclercq, J. (1960). Las grandes líneas de la filosofía moral. Madrid: Biblioteca Hispánica de Filosofía.

Miro Quesada Rada, F. (2013). Introducción a la ciencia política (tercera ed.). Lima: Grijley.
Ortega y Gasset, J. (1923). El tema de nuestro tiempo. Madrid: Calpe.

Pásara, L. (2014). Una reforma imposible - La justicia latinoamericana en el banquillo. Lima: Fondo Editorial Universidad la Católica.

Quiroz, A. (2014). Historia de la corrupción en el Perú. Lima: Instituto de Estudios Peruanos.

Reboul, O. (1999). Los valores de la educación. Madrid: Idea Universitaria.

Sánchez Azcona, J. (2005). Ética y poder (quinta ed.). México: Editorial Porrúa.

Villalobos Caballero, M. A. (2010). El derecho como reflexión filosófica. Lima: El Renacer. 